\title{
Self-monitoring Lifestyle Behavior in Overweight and Obese Pregnant
}

\section{Women: Qualitative Findings}

\author{
Carol Shieh; Claire Burke Draucker
}

\begin{abstract}
Background: Excessive maternal gestational weight gain increases pregnancy and infant complications. Self-monitoring has been shown to be an effective strategy in weight management. Literature, however, is limited in describing pregnant women's engagement in selfmonitoring. Aim: This qualitative study explored the experiences of overweight and obese pregnant women who self-monitored their eating, walking, and weight as participants in an intervention for excessive gestational weight gain prevention. Methods: Thirteen overweight and obese pregnant women participated in semi-structured interviews. Reflexive iteration data analysis was conducted. Findings: Five themes were identified: making self-monitoring a habit, strategies for self-monitoring, barriers to self-monitoring, benefits of self-monitoring, and drawbacks of self-monitoring. The women viewed self-monitoring as a "habit" that could foster a sense of self-control and mindfulness. Visual or tracing aids were used to maintain the selfmonitoring habit. Forgetting, defective tracking aids, complexities of food monitoring, and life events could impede self-monitoring. Unable to keep up with self-monitoring or to achieve goals created stress. Conclusions: Self-monitoring is a promising approach to weight management for overweight and obese pregnant women. However, healthcare providers should be aware that, although women may identify several benefits to self-monitoring, for some women, consistently trying to track their behaviors is stressful.
\end{abstract}

Keywords: self-monitoring, excessive gestational weight gain, pregnancy, qualitative research, obesity

This is the author's manuscript of the article published in final edited form as:

Shieh, C., \& Draucker, C. B. (2018). Self-monitoring Lifestyle Behavior in Overweight and Obese Pregnant Women: Qualitative Findings. Clinical Nurse Specialist, 32(2), 81. https://doi.org/10.1097/NUR.0000000000000355 
Self-Monitoring Lifestyle Behavior in Overweight and Obese Pregnant Women: Qualitative Findings

Maternal obesity and excessive gestational weight gain are associated with infant mortality, maternal weight retention during postpartum, and further adiposity years after birth for the mother and the infant. ${ }^{1,2,3,4}$ Based on the belief that they are "eating for two," many pregnant women consume more food than necessary. ${ }^{5}$ In addition, because some pregnant women fear that engaging in physical activity will harm their babies, they become more sedentary as pregnancy advances and defer regular exercise and weight management until after their babies are born. ${ }^{6}$ Lifestyle interventions, focusing on improving diet and/or exercise, have the potential to reduce the risk of excessive gestational weight gain by $20 \% .^{7}$ Self-monitoring of diet and exercise, a cognitive behavior strategy, has gained its importance in weight management. Engaging pregnant women in self-monitoring lifestyle changes, however, has yet to be studied.

The Pew Research Center found that $60 \%$ of 3,014 adults in a US national survey selfmonitored their weight, diet, or exercise. ${ }^{8}$ Self-monitoring is "the act of systematically observing and recording aspects of one's own behavior and internal and external environmental events thought to be functionally related to that behavior"9 (p. 411). Self-monitoring has long been used as an assessment method to collect pre-treatment data as well as to assess treatment effectiveness and compliance. ${ }^{10}$ More recently, self-monitoring has been adopted as a lifestyle behavior change strategy. Through meta-analysis and systematic review, behavior scientists and obesity researchers conclude that self-monitoring could be an effective strategy for increasing healthy eating and physical activity and improving weight outcomes. ${ }^{11,12}$

Self-monitoring, a cognitive-behavioral approach, requires two phases of personal action: measurement and performance improvement. During the measurement phase, a person observes, measures, and records a target behavior or outcome. Self-monitoring data can be 
collected with or without the assistance of equipment and recorded in paper-and-pencil logs, computerized diaries, or daily checklists. ${ }^{13}$ In the performance improvement phase, the person evaluates monitored data against a reference value and subsequently develops short- and longterm improvement plans independently or in consultation with a professional to maximize or sustain the behavior change and achieve a health-related goal. ${ }^{14}$ Interventions that ask participants to record self-monitoring data, share self-monitoring results with others (e.g., researchers or care providers), receive immediate rather than delayed feedback, and use objective rather than self-report measures experience greater behavior change and more positive outcomes. ${ }^{15}$

Cohen et al. ${ }^{16}$ theorized that self-monitoring facilitates clients' sense of control, autonomy, and self-efficacy as well as enhances a collaborative relationship between a care provider and a client. While some studies have examined targeted health outcomes of selfmonitoring, only a few have explored persons' perceived benefits of self-monitoring. A previous study on persons with HIV, for example, revealed that self-monitoring encouraged selfexpression and resulted in an increased sense of well-being. ${ }^{17}$

Similarly only a few studies have identified perceived facilitators of and barriers to selfmonitoring. In one study of food intake, physical activity, and weight loss in non-pregnant overweight and obese adults, limited organizational skills and competing responsibilities were reported as barriers to self-monitoring. ${ }^{18}$ In another study of self-monitoring of skin changes to prevent melanoma, patients' limited experience with and cautious attitudes toward technology were reported to be barriers to self-monitoring when smartphones, laptop computers, or tablets were used. ${ }^{19}$ Other studies found that patients with diabetes did not self-monitor blood sugar regularly if no hypo- or hyper-glycemic symptoms were experienced. ${ }^{20,21}$ 
Understanding how people experience self-monitoring and eliciting their views of the facilitators of and barriers to self-monitoring will provide foundational information needed to develop and refine self-monitoring interventions. No studies have investigated these factors in a population of overweight and obese pregnant women who are engaged in behavioral selfmonitoring to prevent excess gestational weight gain. Such studies are needed as these women are a unique group whose health behavior has implications for infant outcomes. The aims of this study, therefore, were to (a) describe the experiences of overweight and obese pregnant women engaged in an intervention in which they monitored their eating, walking, and weight gain and (b) obtain the women's perceptions relative to facilitators of and barriers to self-monitoring and its benefits beyond weight management.

\section{Methods}

\section{Design}

This qualitative study was part of a pilot test of an eight-week self-monitoring intervention for overweight and obese pregnant women to prevent excessive gestational weight gain. The pilot test and results were presented elsewhere. ${ }^{22}$ For this qualitative study, individual in-person semi-structured interviews were conducted to explore women's experiences with selfmonitoring of healthy eating, walking and weight after participating in the intervention for at least four weeks. A reflexive iteration process was used for data analysis. ${ }^{23}$ This analysis process involved "visiting and revisiting the data and connecting them with emerging insights, progressively leading to refined focus and understandings" (p. 77). The study was approved by the Indiana University Institutional Review Board. Written informed consent was obtained from all participants.

\section{Participants and Settings}


To participate in this qualitative study, participants must have completed at least four weeks of self-monitoring. Of the 22 women initially enrolled in the self-monitoring intervention, 13 participated in this qualitative study, inclduing 12 completing self-monitoring for eight weeks and one for four weeks. Other inclusion criteria based on the eight-week self-monitoring intervention were as follows: (a) singleton pregnancy of at least 14 weeks gestation, (b) prepregnancy BMI $=25$ to 40, (c) able to speak and read English, and (d) no obstetric, medical, or psychiatric problems that would restrict diet or physical activity or ability to perform selfmonitoring or to engage in meaningful conversation.

The women were recruited during their first prenatal visits to two prenatal clinics in a Midwestern city by research staff. One clinic was located in a community health center and another belonged to a health network. Racial and ethnic distributions in both prenatal clinics were similar: $60 \%$ American Americans, 30\% Caucasians, and 10\% others.

\section{Study procedure}

In the self-monitoring intervention, each participant received a weight scale, a food measuring cup, a water bottle, and a pedometer. In the first four weeks of the self-monitoring intervention, pregnant women self-monitored weight (Weeks 1 to 4), vegetable intake (Week 2), fruit intake (Week 3), and low fat protein/dairy intake (Week 4). In the second four weeks, participants self-monitored weight and walking (Weeks 5 to 8), low fat protein/dairy intake (Week 7), and low or no-sugar-added beverage intake (Week 8).

Recommended goals for weight gain, healthy eating and walking were given to the women. The recommendations were that overweight women should gain no more than $.75 \mathrm{lbs}$. each week and 15 to $25 \mathrm{lb}$. throughout the pregnancy and that obese women should gain no more than $0.5 \mathrm{lbs}$. each week and 11 to $20 \mathrm{lbs}$. throughout the pregnancy. ${ }^{24}$ Healthy eating goals 
included eating 3 cups of vegetables/day, 2 cups of fruits/day, low fat protein or dairy foods 3 times/day, and low or no-sugar-added beverages 3 times/day. ${ }^{25}$ Exercise goals included walking 30 minutes/day for at least 5 days/week. ${ }^{26}$ The women recorded self-monitoring data related to these goals daily in logs and mailed the logs to the research office weekly.

For this qualitative study, each woman was explained by research staff about the semistructured interview upon enrollment into the self-monitoring intervention and informed consent was obtained. The first author conducted the interviews. To build a pre-interview relationship, the first author called or emailed each woman 3 to 7 days before a scheduled interview to introduce herself and to confirm a woman's continued willingness to participate in the interview. Of the 13 women, 10 were interviewed in a private patient room at the prenatal clinics and 3 were interviewed by phone.

The women were first asked the following open-ended question: Please tell me about your experience in checking your weight, eating, and walking for the past 8 (or 4) weeks? Additional questions to solicit more focused responses were as follows: (a) What made it hard to keep track of your weight, what you ate, and how long you walked? (b) What helped you to achieve your goals each week? (c) What would you do differently if you were to do it again? The interviews lasted approximately 30 minutes, and each participant received a gift card of \$20. The interviews were audio-taped and transcribed verbatim.

\section{Data Analysis}

The first author and a $\mathrm{PhD}$ nursing student conducted the data analysis. The first author is an expert in prenatal health promotion and content analysis. The doctoral student has an undergraduate degree in exercise science and has experience in a home visitation program for low income pregnant women. They read the entire transcripts several times in order to become 
familiar with their content as a whole. They independently extracted relevant text units, which are sentences or paragraphs relevant to the study purpose, and coded each with a label that captured its essential meaning. For instance, a code of "visual cue" was assigned to the sentence, "I look at a calendar and see what day it is, and that keeps me on track." They compared and discussed the codes until they reached consensus on the best labels for each text unit. They then grouped codes with similar meanings to develop categories. Similar categories were grouped into five common themes, and a theoretical schema to describe the relationships among the themes was developed by the first author. Both coders discussed and modified the schema by again reviewing the transcripts. To enhance the credibility of the findings, the codes, categories, themes, and final schema were then reviewed by the second author, an expert in qualitative research methodology, who confirmed the analytic decisions made in developing the schema.

\section{Results}

\section{Participants}

Table 1 shows demographic and obstetric information of the 13 women. The mean age of the women was 29.5 years. More women were obese (69\%) than overweight $(31 \%)$. The majority were African American (77\%), not married (69\%), and had had a previous pregnancy $(77 \%)$. Most (69\%) were in their third trimester of pregnancy at the time of the interview.

\section{Common Themes and Their Relationships}

Figure 1 presents the theoretical schema that depicts the five major themes, the categories that comprise each theme, and the proposed relationships among the themes. Table 2 lists the themes, the categories, and several quotes that represent each of the categories. Each theme is described below.

Theme 1: Making self-monitoring a habit. Many women suggested that selfmonitoring needed to become an automatic, regular activity or something one gets "used to 
doing." During the intervention, the women established the habit of self-monitoring in one of two ways - they either enhanced self-monitoring practices they already had developed or they developed new self-monitoring practices. Some women stated that self-monitoring was not "extra work" for them because they had been doing some form of self-monitoring prior to the intervention, whereas other women had to make efforts to develop new habits of self-monitoring as they had not engaged in this practice previously.

Theme 2: Strategies for self-monitoring. The women identified two strategies that helped them to self-monitor: visual reminders and tracking aids. Several kept their monitoring logs in plain sight, such as on the refrigerator, in the middle of a table, or next to a weight scale. Calendars were also used to keep them "on track." The women mentioned using tracking aids, including measuring cups, pedometers, and weight scales, to help with their self-monitoring. They used these aids not only to estimate the quantity of their food intake or to track the distance they walked but also to motivate them to "get up and move around" and change their behaviors, such as cutting back on what they were eating.

Theme 3: Barriers to self-monitoring. Four barriers to self-monitoring were reported: forgetting, defective tracking aids, the complexities of food monitoring, and life events. Several women acknowledged that they often forgot to weigh themselves, record their weight, write down what they ate, or put on their pedometer before going for a walk. Some women attributed their forgetfulness to being disorganized. One women said she would write her tracking information on a piece of paper but then she "had to go find the piece of paper." Tracking aids that did not work well were another barrier to self-monitoring. A couple of women had trouble with weight scales that seemed to fluctuate, and others had trouble with their pedometers not working properly. A third barrier was the complexities of food monitoring. Some women were 
uncertain about how to determine if foods were "low fat" or "protein rich." Other women had trouble quantifying foods that could not be measured in cups such as pieces of fruit. Life events, such as traveling or family deaths, could interfere with daily routines and therefore made the women "fall off the wagon" for self-monitoring.

Theme 4: Benefits of self-monitoring. The women identified four benefits, beyond weight management goals, as a result of their self-monitoring activities. These benefits included trying new things, being mindful, being in control, and planning ahead. Some of the women tried new ways to eat healthy as a result of self-monitoring. They tried new foods such as yogurt or certain fruits, replaced processed items with fresh foods, and cooked at home rather than eating fast foods. The women became more mindful of their eating and activity choices. They were more "conscious" of their weight and more attuned to what they were eating, how much they were eating, and how active they were. They felt more in control due to the self-monitoring. Several remarked that although the researchers "led" them a bit, they were in charge of their decisions and behaviors and accomplished their successes on their own. They "set their mind" to make changes and "just do it." Many women reported that self-monitoring encouraged them to "plan ahead" what to eat, when to eat, and where to walk.

Theme 5. Drawbacks of self-monitoring. Although most women espoused the benefits of self-monitoring, some suggested that it could become stressful. Some became frustrated when they could not "keep up with" self-monitoring or when they were unable to achieve goals. Some felt they "did not eat enough and felt tired and drained." Others were distressed when they could not "hit that weight mark" or they would "go over" their weight gain target goal.

\section{Discussion}

Thirteen overweight or obese pregnant women were interviewed about their experiences 
with self-monitoring their eating, walking, and weight as participants in an intervention aimed to prevent excessive gestational weight gain. Findings were summarized into a theoretical schema that included five major themes: making self-monitoring a habit, strategies for self-monitoring, barriers to self-monitoring, benefits of self-monitoring, and drawbacks of self-monitoring.

The finding that participants strived to make self-monitoring a habit was promising since the long-term effectiveness of this approach rests on it becoming a routine part of persons' daily lives. ${ }^{27}$ Although we recognize that the intervention was brief and we do not know if the participants continued the self-monitoring on a regular basis after the intervention ended, they did view the practice as one that needed to be integrated into their everyday lives and to be sustained.

The women in our study reported that self-monitoring gave them a sense of self-control. This finding is in support of a proposition made by Cohen and colleagues that self-monitoring can increase persons' sense of efficacy and autonomy. ${ }^{16}$ Further, the finding that women in our study articulated a sense of mindfulness indicates that self-monitoring fosters a cognitive change and can make persons become more self-aware and self-empowered. ${ }^{17}$

Though our participants found the use of everyday visual reminders, such as calendars or paper logs attached to a refrigerator, helpful in facilitating monitoring, other researchers have investigated the use of technology (e.g., smartphones, wireless Internet, patient digital assistants) to remind persons to self-monitor with mixed results. In one study, sending text messages to prompt pregnant women to eat a healthy snack or go for a walk was found to be effective in preventing the women from gaining excessive gestational weight. ${ }^{28}$ In another study using a personal digital assistant (PDA) to send automated messages to study participants to remind them to track physical activity status, however, found no differences in mean number of weekly 
entries between participants using PDAs and those using paper records. ${ }^{29}$ Having visual reminders in clear view might be more important than how reminders are sent to persons who are doing self-monitoring. Nevertheless, future research may investigate how personal preference regarding how and when a reminder is received influences self-monitoring practices and behavior outcomes. Our findings about forgetfulness and life events interfering with monitoring are consistent with the findings of Burke and colleagues, ${ }^{18}$ who reported that participants who were not able to keep up with self-monitoring often had organizational deficiencies or competing responsibilities.

Although most studies find that self-monitoring is not associated with negative psychological outcomes, ${ }^{30}$ some women in our study did report that it could be stressful due to the demands of self-monitoring and failure to achieve goals. Similarly, another study revealed that although self-monitoring of blood sugar gave some participants a sense of confidence, freedom, certainty, and peace of mind, it made others feel frustrated, anxious, or helpless. ${ }^{14}$ More research is thus needed about the negative repercussions of unsuccessful self-monitoring in pregnant women. Because continued failure in achieving therapeutic or behavior goals may result in discontinuation of self-monitoring, ${ }^{21}$ it is likely that additional support would be necessary for persons who fail to meet their objectives.

Our findings should be considered in the context of several limitations. Because the study was a preliminary pilot study of the intervention, the sample size was small, the intervention was conducted at only one geographical location, and the sample had little racial diversity. Furthermore, our study included only overweight and obese pregnant women, whose experiences in self-monitoring may differ from those experienced by pregnant women who are normal weight or underweight. 


\section{Practice Implications}

Despite these limitations, the schema we developed does have implications for practice. Our findings suggest that clinical nurse specialists can ascertain ways pregnant women may already be engaged in self-monitoring to improve healthy eating and physical activity and discuss with them how those practices might be enhanced to ensure proper gestational weight gain. Clinical nurse specialists should reinforce the notion that self-monitoring is a habit that needs to be well integrated into everyday routines and that self-monitoring of health behavior and gestational weight may help pregnant women gain a sense of self-control and be more mindful of their healthy eating and physical activity.

The findings also provide some possible strategies that can assist pregnant women to successfully self-monitor as well as point to some common barriers that can be discussed by clinical nurse specialists. For example, clinical nurse specialists can discuss with pregnant women when they might be most at risk of "forgetting" to self-monitor and how they might continue the practice when their daily routines are interrupted. Issues related to dealing with the complexities of self-monitoring can be addressed by educational approaches in which topics such as how to determine the quality and quantity of a wide variety of foods can be discussed. Clinical nurse specialists should also be aware that although pregnant women identify several benefits to self-monitoring, some women experience stress if they are unable to consistently track their behaviors or achieve their goals. The stress of self-monitoring should be openly discussed with pregnant women so that they do not attribute difficulties with establishing the habit of selfmonitoring as a personal failing. If necessary, additional support may need to be provided for pregnant women who experience stress while performing self-monitoring.

\section{Conclusions}


The experiences of overweight and obese pregnant women engaged in self-monitoring their eating, walking, and weight gain were explored with semi-structured interviews. To continue self-monitoring on a regular basis, pregnant women would need to integrate it into their daily life routines. The schema developed from this study increases our understanding of what helps pregnant women in self-monitoring, what gets in the way, what benefits are derived from self-monitoring, and what disadvantages might be associated with this approach. The schema can provide guidance for clinical nurse specialists who are considering integrating self-monitoring strategies into weight management programs for overweight and obese pregnant women. 


\section{References}

1. Amorim AR, Rössner S, Neovius M, Lourenco PM, Linnê, Y. Does excess pregnancy weight gain constitute a major risk for increasing long-term BMI. Obesity. 2007;15(5):1278-1286.

2. Ashley-Martin J, Woolcott C. Gestational weight gain and postpartum weight retention in a cohort of Nova Scotian women. Matern Child Health J. 2014;18(8):1927-1935.

3. Bodnar LM, Siminerio MM, Himes KP, Hutcheon JA, Lash TL, Parisi SM, Abrams B. Maternal obesity and gestational weight gain are risk factors for infant death. Obesity. 2016;24(2):490-498.

4. Declercq E, MacDorman M, Cabral H, Stotland N. Prepregnancy body mass index and infant mortality in 38 U.S. States, 2012-2013. Obstet \& Gynecol. 2016;127(2):279-287.

5. Copelton DA. You are what you eat: nutritional norms, maternal deviance, and neutralization of women's prenatal diets. Deviant Behav. 2007;28(5):467-494.

6. Weir Z, Bush J, Robson SC, McParlin C, Rankin J, Bell R. Physical activity in pregnancy: A qualitative study of the beliefs of overweigh and obese pregnancy women. BMC Pregnancy Childbirth. 2010;10:18.

7. Muktabhant B, Lawrie TA, Lumbiganon P, Laopaiboon M. Diet or exercise, or both, for preventing excessive weight gain in pregnancy. Cochrane Database Syst Rev. 2015; Issue 6:CD007145

8. Fox S, Duggan M. Tracking for health. Pew Research Center's Internet \& American Life Project. Pew Research Center. 2013. http://www.pewinternet.org/2013/01/28/tracking-forhealth/

9. Cone JD. Introduction to the special section on self-monitoring: A major assessment method in clinical psychology. Psychol Assessment. 1999;11(4):411-414.

10. Korotitsch WJ, Nelson-Gray RO. An Overview of Self-Monitoring Research in Assessment and Treatment. Psychol Assessment. 1999;11(4):415-425.

11. Burke LE, Wang J, Sevick MA. Self-monitoring in weight loss: A systematic review of the Literature. J Am Diet Assoc. 2011;111(1):92-102.

12. Michie S, Abraham C, Whittington C, McAteer J. Effective techniques in healthy eating and physical activity interventions: A meta-regression, Health Psychol. 2009;28(6):690701.

13. Barton KA, Blanchard EB, Veazey C. Self-monitoring as an assessment strategy in behavioral medicine. Psychol Assessment. 1999;11(4):490-497.

14. Hortensius J, Kars MC, Wierenga WS, Kleefstra N, Bilo HJ, van der Bijl JJ. Perspectives of patients with type 1 or insulin-treated type 2 diabetes on self-monitoring of blood glucose: a qualitative study. BMC Public Health. 2012;12:167.

15. Harkin B, Webb TL, Chang BP, Prestwich A, Conner M, Kellar I, Benn Y, Sheeran P. Does monitoring goal progress promote goal attainment? A meta-analysis of the experimental evidence. Psychol Bull. 2016;142(2):198-229. http://dx.doi.org/10.1037/bul0000025

16. Cohen JS, Edmunds JM, Brodman DM, Benjamin CJ, Kendall PC. Using self-monitoring: Implementation of collaborative empiricism in cognitive-behavioral therapy. Cogn Behav Prac. 2013;20(4):419-428.

17. Swendeman D, Ramanathan N, Baetscher L, Medich M, Scheffler A, Comulada S, Estrin D. Smartphone Self-monitoring to support self-management among people living with HIV. J Acquir Immune Defic Syndrs. 2015;69(S1):S80-S91. 
18. Burke LE, Swigart V, Warziski Turn M, Derro N, Ewing LJ. Experiences of selfmonitoring: Success and struggles during treatment for weight loss. Qual Health Res. 2009; 19(6):815-828.

19. Hall S, Murchie P. Can we use technology to encourage self-monitoring by people treated for melanoma? A qualitative exploration of the perceptions of potential recipients. Supportive Care Cancer. 2014;22(6):1663-1671.

20. Eborall KC, Dallosso HM, McNicol S, Speight J, Khunti K, Davies M, S. Heller SR. Explaining engagement in self-monitoring among participants of the DESMOND selfmonitoring Trial: a qualitative interview study. Fam Prac. 2015;32(5):596-602.

21. Peel E, Douglas M, Lawton L. Self-monitoring of blood glucose in type 2 diabetes: longitudinal qualitative study of patients' perspectives. BMJ. 2007;335(7618):493.

22. Authors. Feasibility and potential benefits of a self-monitoring enhanced lifestyle intervention to prevent excessive gestational weight gain in overweight and obese women. JOGNN. 2017;46(2):182-196.

23. Srivastava P, Hopwood N. A practical iterative framework for qualitative data analysis. Int J Qual Methods. 2009;8(1):76-84.

https://ejournals.library.ualberta.ca/index.php/IJQM/article/view/1169/5199

24. Institute of Medicine. Weight gain during pregnancy: Reexamining the guidelines. Washington, DC: The National Academies Press, 2009.

25. U.S. Department of Agriculture. Nutritional needs during pregnancy. Retried from http://www.choosemyplate.gov/nutritional-needs-during-pregnancy

26. Academy of Nutrition and Dietetics. Position paper: Nutrition and lifestyle for a healthy pregnancy outcome. J Acad of Nutr Diet. 2014;114(7):1099-1103.

27. Rothman AJ, Baldwin AS, Hertel AW, Fuglestad PT. Self-regulation and behavior change. In Vohs KD, Baumeister RF, eds. Handbook of self-regulation, research, theory, and application. $2^{\text {nd }}$ ed. New York, NY: Guilford Press, 2011.106-122.

28. Soltani H, Duzbury AMS, Arden MA, Dearden A, Furness PJ, Garland C. Maternal obesity management using mobile technology: A feasibility study to evaluate a text messaging based complex intervention during pregnancy. Journal of Obesity. 2015: Article ID 814830. http://dx.doi.org/10.1155/2015/814830

29. Conroy MB, Yang K, Elci OU, Gabriel KP, Styn MA, Wang J, Kriska M, Sereika S, Burke LE. Physical activity self-monitoring and weight loss: 6-month results of the SMART trial. Med Sci Sport Exer. 2011;43(8):1568-1574.

30. Phelan S, Jankovitz K, Hagobian T, Abrams B. Reducing excessive gestational weight gain: lessons from the weight control literature and avenues for future research. Womens Health. 2011;7(6):641-661. 
Table 1. Demographic and Obstetric History of Study Participants ( $\mathrm{N}=13)$

\begin{tabular}{|c|c|c|c|}
\hline Variables & $\mathrm{N}(\%)$ & Variables & $\mathrm{N}(\%)$ \\
\hline Age (years), Mean $\left(\mathrm{SD}^{\mathrm{a}}\right)$ & $29.5(5.9)$ & Number of Pregnancy, Mean (SD) & $3.5(1.8)$ \\
\hline $\begin{array}{l}\text { Ethnicity } \\
\text { African American } \\
\text { White } \\
\text { Multiracial }\end{array}$ & $\begin{array}{l}10(76.9) \\
2(15.4) \\
1(7.7)\end{array}$ & $\begin{array}{l}\text { BMI, Mean (SD) } \\
\text { Obese } \\
\text { Overweight }\end{array}$ & $\begin{array}{l}31.1(3.0) \\
9(69.2) \\
4(30.8)\end{array}$ \\
\hline $\begin{array}{l}\text { Education } \\
\text { Grade }<=12 \\
\text { Some College/College } \\
\text { Master/PhD }\end{array}$ & $\begin{array}{l}5(38.5) \\
5(38.5) \\
3(23.1)\end{array}$ & $\begin{array}{l}\text { First Pregnancy } \\
\text { No } \\
\text { Yes }\end{array}$ & $\begin{array}{l}10(76.9) \\
3(23.1)\end{array}$ \\
\hline $\begin{array}{l}\text { Marital Status and FOB } \\
\text { Married and Live with FOB } \\
\text { Single and Live with FOB } \\
\text { Single and Not Live with FOB } \\
\text { Divorced/Separated and Live with } \\
\text { FOB }\end{array}$ & $\begin{array}{l}4(30.8) \\
2(15.4) \\
6(46.2) \\
1(7.7)\end{array}$ & $\begin{array}{l}\text { This Pregnancy Planned } \\
\text { No } \\
\text { Yes }\end{array}$ & $\begin{array}{c}7(53.8) \\
6(46.2)\end{array}$ \\
\hline $\begin{array}{l}\text { Household Income } \\
\text { Less than } \$ 25 \mathrm{k} \text { a year } \\
\$ 25 \mathrm{k}-\$ 50 \mathrm{k} \text { a year } \\
\text { More than } \$ 100 \mathrm{k} \text { a year }\end{array}$ & $\begin{array}{l}7(53.8) \\
5(38.5) \\
1(7.7)\end{array}$ & $\begin{array}{l}\text { Social/Health Services Used, } \mathrm{N}= \\
10 \text { (choose multiple) } \\
\text { WIC } \\
\text { Food Stamps/TANF } \\
\text { Housing } \\
\text { Genetic Counseling } \\
\text { Childbirth class }\end{array}$ & $\begin{array}{l}7(70.0) \\
6(60.0) \\
2(20.0) \\
1(10.0) \\
1(10.0)\end{array}$ \\
\hline $\begin{array}{l}\text { Pregnancy trimester at interview } \\
\text { Second ( } \leq 27 \text { weeks) } \\
\text { Third ( }>27 \text { weeks })\end{array}$ & $\begin{array}{l}4(30.8) \\
9(69.2)\end{array}$ & & \\
\hline
\end{tabular}

${ }^{\mathrm{a} S D}$ : Standard deviation

${ }^{b}$ FOB: Father of baby 
Table 2: The Experience of Self-Monitoring by Pregnant Women: Themes, Categories, and Quotes

\begin{tabular}{|c|c|c|}
\hline Themes & Categories & Representative Quotes \\
\hline \multirow[t]{5}{*}{$\begin{array}{l}\text { Making Self- } \\
\text { Monitoring a } \\
\text { Habit }\end{array}$} & $\begin{array}{l}\text { Enhancing } \\
\text { existing self- } \\
\text { monitoring } \\
\text { habits }\end{array}$ & $\begin{array}{l}\text { It wasn't hard because basically I'm monitoring stuff that I already do. I mean it just, } \\
\text { the fact that I'm measuring basically on those weeks that I have to measure, cup-wise, } \\
\text { but I mean other than that I'm already doing that on a daily basis so it wasn't hard at } \\
\text { all. }\end{array}$ \\
\hline & & $\begin{array}{l}\text { I just always had a little bit, I always try to monitor it just because I'm active, and } \\
\text { because of my weight in general, even being active, it's always something I kind of } \\
\text { monitored, and it's always trying to eat healthy because it's fuel for the body, and stuff } \\
\text { like that. So it's already kind of engrained. }\end{array}$ \\
\hline & $\begin{array}{l}\text { Developing } \\
\text { new self- } \\
\text { monitoring }\end{array}$ & $\begin{array}{l}\text { Like this morning I just got up and I looked at the scales because I was so used to it at } \\
\text { this point. Now I'm used to doing it. It just became a normal part of life at this point. }\end{array}$ \\
\hline & habits & $\begin{array}{l}\text { As soon as I started working, when I put my walkie on, I put my little thing on, so that } \\
\text { kept me tracking making sure I knew exactly when I put it on. }\end{array}$ \\
\hline & & $\begin{array}{l}\text { Usually it was just monitor your weight, which isn't terrible, because you get on the } \\
\text { scale in the morning and you get into that habit. }\end{array}$ \\
\hline
\end{tabular}

\begin{tabular}{|c|c|c|}
\hline $\begin{array}{l}\text { Strategies for } \\
\text { Self- } \\
\text { Monitoring }\end{array}$ & $\begin{array}{l}\text { Using visual } \\
\text { reminders }\end{array}$ & $\begin{array}{l}\text { I had kept my paper on the refrigerator so that was like I go in the kitchen all the time. } \\
\text { So I'm like you cannot miss it } \\
\text { I have it sitting right on the table. It's never out of my eyesight. So it sits right on my } \\
\text { table so I won't miss it or I won't miss a day. }\end{array}$ \\
\hline
\end{tabular}

Keeping the log by bed and when I woke up I see it and wouldn't forget it.

I look at a calendar and see what day it is, and that keeps me on track. 
Using tracking Honestly putting it in that measuring cup made it seem like it was more than what I aids would normally put. If I took two spoons, two serving spoons full that it would be half that cup size. So eating like one cup of vegetables or one cup of fruit I was like, wow, I wasn't eating enough

As far as the motivation for walking, the pedometer helped a whole lot so that I would actually track that I am doing walking, that I've taken this time to actually get up and move around and stay active.

But basically I have a scale now that I can check my weight and see what I'm doing with that or oh I might be eating too much, this serving cup, so let me cut down, or whatever.

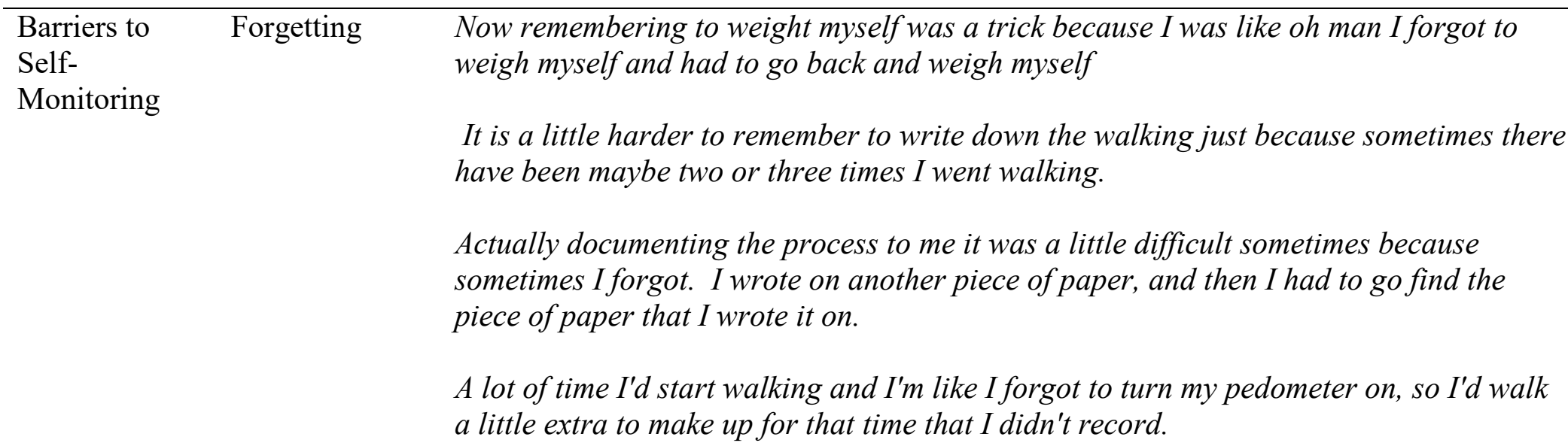

Defective tracking aids

The scale kind of messed up on me. One time it said I was one size and I would get back on it and then I would be another size. So I was a little confused about that but other than that, no, I can't think of anything.

The only suggestion and the only issue that I did have out of it was the fluctuation of the scale. I'm not sure if it was me or if it was the scale. That's the only thing. So I'm not sure if it was something going on with the scale itself but maybe looking into that. 
Complexities Maybe pictures of portion sizes or emphasis on the fact that you do not need to eat for of food two people

monitoring

The one thing that was sometimes challenging with the fruits were like say if you eat an apple, then how do you document that because you don't necessarily document as cups, but is it a small, medium, large.

I'd have to actually measure things and try to figure out, I don't know how to quantify what I ate, so how many or what ounces, or that sort of thing.

Sometimes I wondered if people know what you mean by a low-fat dairy, or a meat, or a protein. I think, I forgot how you put it down. But, maybe a list of what you mean when you use that term.

Life events $\quad$ My mom passed away in July. I kind of fell off the wagon a little bit as far as recording, but when you're going through a crisis or something writing stuff down was the last thing on my mind.

Probably just like on the off days when I wasn't working. Sometimes you didn't really feel like getting up and actually going and doing your walks.

I think there were a couple of times when I traveled and making sure to take the scale with me and remembering that kind of stuff was the biggest issue.

I mean it's hard when you have to keep track of everything when you are busy too.

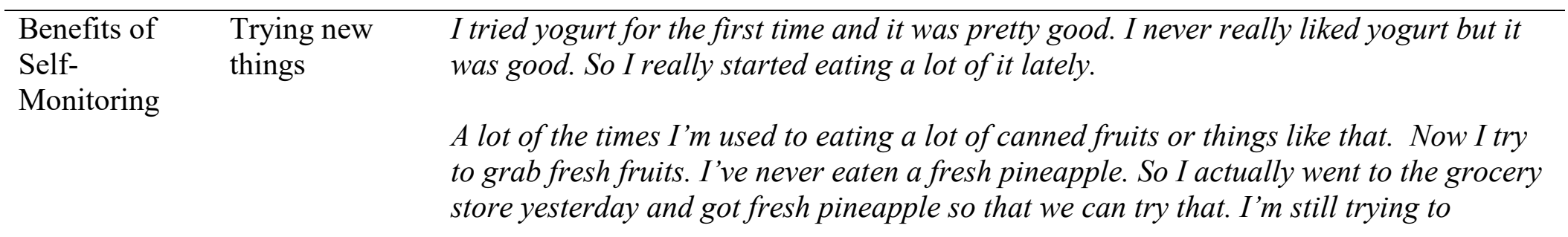


broaden my horizons and look at more things that I can do that's healthy and not just fix the same old thing every single day.

I didn't want to lose too much weight during pregnancy, but I cooked some food at home and that might have been ... no more fast food. I cook myself now. No more fast food.

Being mindful It actually helped me think mentally, okay, so if I eat this, I don't need to eat nothing else because to me sometimes I feel like I'm not eating enough when I know well enough I did eat enough.

But for me it at least made me conscious of what I was eating. It made me think about things a little bit more.

The food, like monitoring weight, that was just, it was just being more mindful of my choices from like lunch, and kind of dinner, and sometimes breakfast, what I ate, just to make sure I got certain foods in.

Just having to record it every day and go oh I didn't eat that, let me go and ... especially because I'd record before dinner or something, I'd be like oh I should eat more of that.

Being in Sometimes it helps to let the patient lead just a little bit without taking complete control control of everything and making her feel like it's all about the baby and you've just got to get in where you fit in. Let them be involved in making the decisions.

I can't think of anything because they didn't really take me through anything. I really did everything on my own.

It's me wanting to do, you know what I'm saying, what I had to do to stay on track, so I mean I really didn't have to have any push behind me to do it, so there wasn't any barriers that I needed to try to help myself get through to do that, so it's something that I know I had my mind set on and to do it, so I just did it. 
Planning ahead It made me plan a little bit ahead of time what I was going to eat throughout the day to make sure that I would try to meet the goals.

With the physical activity, I actually thought, I had to plan out when I was going to do it to make sure that I had the time and the energy, because I didn't want to wait until so late at night where I would just be so tired and ready to go to bed.

So it definitely makes you keep in mind what did you eat, what did you drink, how did you ... what physical activity are you going to do, and when are you going to do it, and how are you going to do it, until it makes you plan a lot more than you probably normally would.

Drawbacks of Creating stress
Self-
Monitoring

I can honestly say if I wasn't pregnant that wouldn't have been hard to do but being pregnant and her, the baby consuming so much you feel like if you don't eat enough you feel fatigued and you feel tired and drained. So limiting myself to what I have to eat and what I had to do then that was kind of, and I put that on my paper. That was kind of stressful but once again it's a mind over matter thing.

I mean sometimes you worried a little bit that you weren't going to hit that weight mark because you didn't want to go over, but it was pretty easy.

It was sometimes a little stressful just hoping, oh, I hope I didn't go over this week or double checking your weighs and stuff. 
Figure 1. Theoretical Schema of Self-Monitoring Lifestyle Behavior

\section{Strategies for Self-Monitoring}

- Using visual reminders

- Using tracking aids

\section{Barriers to Self-Monitoring}

- Forgetting

- Defective tracking aids

- Complexities of food monitoring

- Life events
Benefits of Self-Monitoring

- Trying new things

- Being mindful

- Being in control

- Planning ahead

Making Self-Monitoring a Habit

- Enhancing existing selfmonitoring habits

- Developing new selfmonitoring habits

Drawbacks of Self-Monitoring

- Creating stress 